\title{
Melanin-Based Coatings as Lead-Binding Agents
}

\author{
Karin Sono, Diane Lye, Christine A. Moore, W. Christopher Boyd, \\ Thomas A. Gorlin, and Jason M. Belitsky
}

Department of Chemistry and Biochemistry, Oberlin College, 119 Woodland Street, Oberlin, OH 44074, USA

Correspondence should be addressed to Jason M. Belitsky, jason.belitsky@oberlin.edu

Received 4 December 2011; Revised 23 January 2012; Accepted 7 February 2012

Academic Editor: Patrick Bednarski

Copyright ( $) 2012$ Karin Sono et al. This is an open access article distributed under the Creative Commons Attribution License, which permits unrestricted use, distribution, and reproduction in any medium, provided the original work is properly cited.

Interactions between metal ions and different forms of melanin play significant roles in melanin biochemistry. The binding properties of natural melanin and related synthetic materials can be exploited for nonbiological applications, potentially including water purification. A method for investigating metal ion-melanin interactions on solid support is described, with lead as the initial target. $2.5 \mathrm{~cm}$ discs of the hydrophobic polymer PVDF were coated with synthetic eumelanin from the tyrosinase-catalyzed polymerization of L-dopa, and with melanin extracted from human hair. Lead $\left(\mathrm{Pb}^{2+}\right)$ binding was quantified by atomic absorption spectroscopy (flame mode), and the data was well fit by the Langmuir model. Langmuir affinities ranged from $3.4 \cdot 10^{3}$ to $2.2 \cdot 10^{4} \mathrm{M}^{-1}$. At the maximum capacity observed, the synthetic eumelanin coating bound $\sim 9 \%$ of its mass in lead. Binding of copper $\left(\mathrm{Cu}^{2+}\right)$, zinc $\left(\mathrm{Zn}^{2+}\right)$, and cadmium $\left(\mathrm{Cd}^{2+}\right)$ to the synthetic-eumelanin-coated discs was also investigated. Under the conditions tested, the Langmuir affinities for $\mathrm{Zn}^{2+}, \mathrm{Cd}^{2+}$, and $\mathrm{Cu}^{2+}$ were $35 \%, 53 \%$, and $77 \%$, respectively, of the Langmuir affinity for $\mathrm{Pb}^{2+}$. The synthetic-eumelanin-coated discs have a slightly higher capacity for $\mathrm{Cu}^{2+}$ on a per mole basis than for $\mathrm{Pb}^{2+}$, and lower capacities for $\mathrm{Cd}^{2+}$ and $\mathrm{Zn}^{2+}$. The system described can be used to address biological questions and potentially be applied toward melanin-based water purification.

\section{Introduction}

While the term "melanin" is widely recognized by the general public, our understanding of the bioorganic chemistry of melanins is far less advanced than for other biopolymers. However, there have been recent advances in the understanding of melanin structure, function, and properties $[1,2]$, as well as in the development of well-defined synthetic mimics $[3,4]$ and melanin-based materials [5, 6]. Melanins display extensive molecular recognition chemistry, with the ability to bind a wide range of organic and inorganic species. The interaction of melanins with metal ions plays a particularly large role in their biochemistry [7]. Current research suggests that the black-to-brown pigment eumelanin is formed via supramolecular assembly, and metal ions may be integral components of this assembly process $[7,8]$. In human melanocytes, eumelanin is produced along with pheomelanin, a chemically distinct yellow-to-red pigment, in organelles known as melanosomes. Melanosomes are thought to play a role in calcium homeostasis [9]. Interactions between metals and melanin have been proposed to play a role in the development of melanoma [10] and may be leveraged for potential treatment [11]. In the substancia nigra region of the brain, the redox balance between iron, dopamine, neuromelanin, and sources of oxidative stress is thought to play a role in Parkinson's disease [12]. Recently, a new form of neuromelanin found widely throughout the brain, nanoparticle aggregates with a eumelanin-like exterior, was shown to be a protective reservoir for heavy metals, including lead [13]. The sequestration of metal ions by melanin has been exploited in forensics and toxicology [14], and most recently, paleontology [15]. Interactions between melanins and metal ions can also be leveraged for nonbiological applications [16, 17], potentially including water purification $[18,19]$.

Eumelanin biosynthesis is initiated by the enzyme tyrosinase, which carries out two successive oxidations of tyrosine, first to L-dopa and then to dopaquinone (Figure 1(a)). Intramolecular ring closure ultimately leads, with and without loss of the carboxylic acid, to the eumelanin monomers 5,6-dihydroxyindole (DHI) and 5,6-dihydroxyindolecarboxylic acid (DHICA), respectively. These are further oxidized to highly reactive indolequinones, which react with 

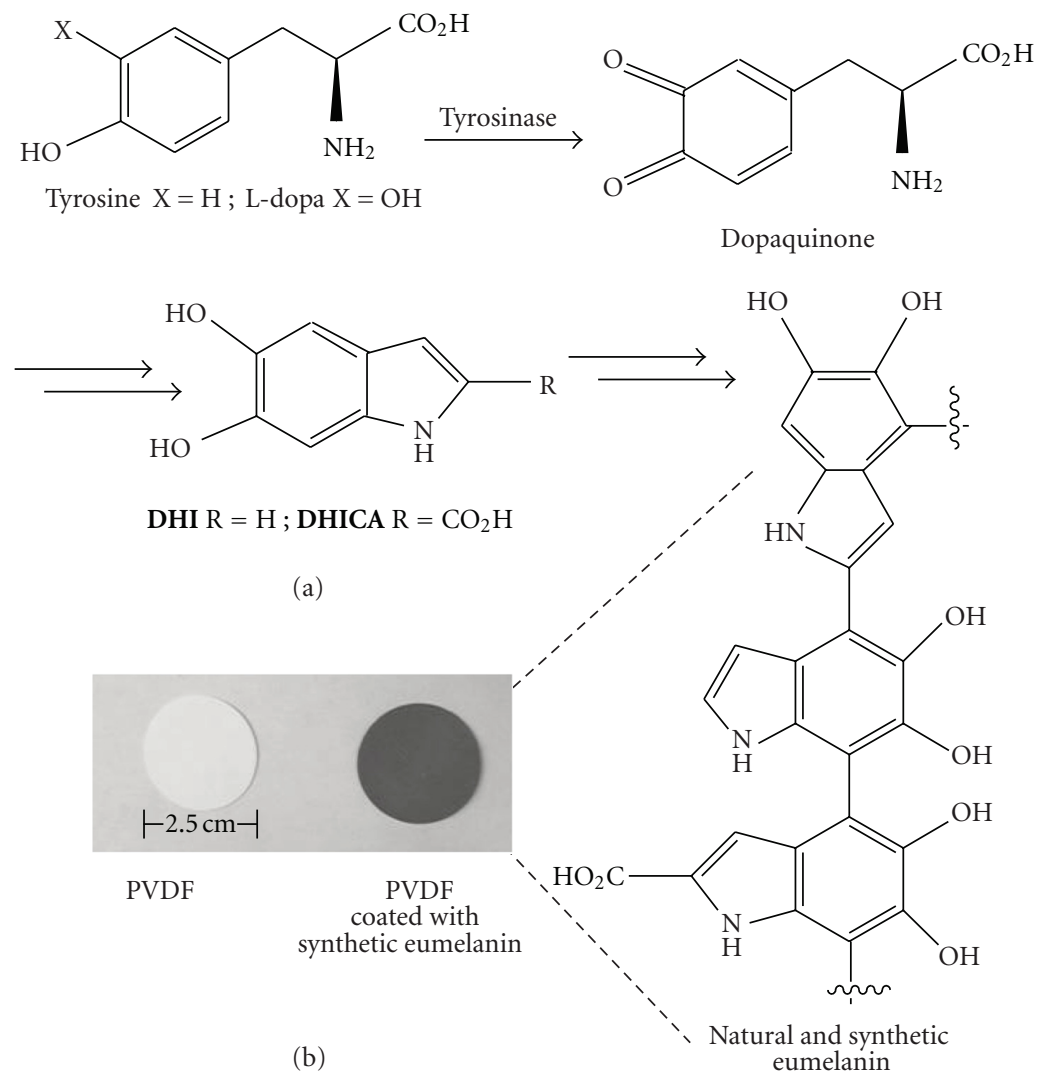

FIGURE 1: (a) Biosynthesis of natural eumelanin and biomimetic production of synthetic eumelanin. (b) $2.5 \mathrm{~cm}$ PVDF disc before (left) and after (right) coating with synthetic eumelanin.

each other and other components of the melanosome to form eumelanin. DHI and DHICA are now thought to form relatively short covalent oligomers that are heterogeneous with respect to both linkages between dihydroxyindole units and their oxidation states. These heterogeneous oligomers aggregate to form nanoparticles, and eumelanin superstructures are formed from these nanoparticles [1-4, 8]. Along with hydrogen bonding and aromatic stacking, metal ions (particularly $\mathrm{Fe}^{3+}, \mathrm{Cu}^{2+}, \mathrm{Zn}^{2+}, \mathrm{Mg}^{2+}$, and $\mathrm{Ca}^{2+}$ ) are thought to provide key bridging interactions between both oligomers and nanoparticles and may also act as templates for different oligomeric and supramolecular structures [7, 8]. Changes in the aggregation and nanoscale morphology of preformed synthetic eumelanin have been observed upon the addition of $\mathrm{Cu}^{2+}$ and $\mathrm{K}^{+}[8,20]$. Endogenously bound metal ions can be removed from natural samples such as Sepia eumelanin from cuttlefish ink and rebound with high affinity [21].

In vitro, under ambient oxygen conditions, conversion of L-dopa to a DHI/DHICA-containing synthetic eumelanin material (Figure 1) is thermodynamically spontaneous and kinetically facile from the dopaquinone oxidation state [22]. Thus, numerous methods can be used to initiate the formation of synthetic eumelanin from L-dopa, including autooxidation, chemical oxidants, and biomimetic catalysis with tyrosinase [22]. The quinone intermediates in these polymerizations are sufficiently reactive that many other compounds can potentially be incorporated covalently into the resulting materials, potentially tuning their properties.
(Nicotine is a physiologically relevant example [23].) Additionally, Messersmith, Ball, and others have found that eumelanin-related polydopamine coatings can adhere to nearly any surface $[5,24]$. Thus, synthetic eumelanin can be readily prepared, modified, and presented in a variety of formats. Whereas synthetic chemistry offers the potential for greater variation, the ability to make use of melanin from renewable natural resources is attractive from a sustainability perspective. Wherever there are people there is hair, such that melanin from human hair [25-27] could be useful for water purification in areas where there are few other resources.

As part of a broader program to understand and modulate [28] eumelanin self-assembly and subsequent molecular recognition, we have developed a convenient method for studying metal ion binding to both synthetic and naturally derived melanin-based materials on solid support. Lead was chosen as initial target due to its toxicity, environmental distribution, and accumulation in neuromelanin [13]. There is great interest in the development of heavy metal sequestration agents based on synthetic systems $[29,30]$, as well as natural, renewable, and/or otherwise-discarded materials [31, 32]. Two recent studies have investigated melanin from squid ink for binding lead $\left(\mathrm{Pb}^{2+}\right)$ and cadmium $\left(\mathrm{Cd}^{2+}\right)[18]$ and fungal melanin secretions for binding chromium $\left(\mathrm{Cr}^{6+}\right)$ [19]. For water purification applications under batch conditions, an advantage of the presentation of melanin as a coating on solid support compared to a free suspension is that the solid support obviates the need for filtration or sedimentation 
steps to remove the suspension. As a research method, the advantages of coatings rather than free suspensions include ease of handling, minimization of the volume of heavy metal waste, and potential for combinatorial variation of synthetic coatings. Importantly, the solid support chosen, polyvinylidene di-fluoride (PVDF), is amenable to coating with both natural and synthetic melanin samples, allowing their direct comparison under identical conditions. Overall the process described here is complementary to other recent approaches for investigating melanin-metal ion interactions [7, 8, 33]. Here we introduce a metal binding assay using PVDF discs coated with synthetic eumelanin and melanin extracted from human hair, with a focus on lead binding.

\section{Experimental}

2.1. Synthetic-Eumelanin-Coated Discs. The production of synthetic eumelanin via the biomimetic oxidation of L-dopa with tyrosinase follows standard practice $[22,23,34-36]$. The discs are prepared in batches of twelve. Polyvinylidene di-fluoride (PVDF) discs are prepared from BioTrace PVDF membrane sheets (Pall) using a $2.5 \mathrm{~cm}$ diameter arch punch. $2.5 \mathrm{~cm}$ PVDF discs are shaken in $\mathrm{MeOH}$ for $\sim 1 \mathrm{~min}$, followed by two water washes ( 6 discs per $50 \mathrm{~mL} \mathrm{H}_{2} \mathrm{O}, 5 \mathrm{~min}$ each). A mushroom tyrosinase (Aldrich) stock solution of 1000 units/mL in sodium phosphate buffer $(50 \mathrm{mM}, \mathrm{pH} 7.0)$ is prepared. L-dopa is dissolved in the same buffer to a concentration of $5.08 \mathrm{mM}(1 \mathrm{mg} / \mathrm{mL}) .84 \mathrm{~mL}$ of freshly prepared L-dopa solution is added to a wide-mouth glass jar followed by $850 \mu \mathrm{L}$ of the tyrosinase stock solution. Twelve PDVF discs are added to this solution $(5.02 \mathrm{mM} \mathrm{L}$-dopa, 10 units $/ \mathrm{mL}$ tyrosinase, $50 \mathrm{mM}$ sodium phosphate, $\mathrm{pH} 7.0$ ), and the jar is shaken at $250 \mathrm{rpm}$ for $\sim 22 \mathrm{hrs}$ at room temperature. After shaking for $\sim 22 \mathrm{hrs}$, the discs are coated synthetic eumelanin and black in appearance. They are washed twice in the sodium phosphate buffer ( 6 discs per $50 \mathrm{~mL}$ buffer, $5 \mathrm{~min}$ each). Synthetic-eumelanin-coated discs are stored immersed in sodium phosphate buffer (50 mM, pH 7.0), in the dark at room temperature.

To determine the amount of synthetic eumelanin per disc, $\geq 10$ discs from different polymerizations were stored in a dessicator until dryness and compared to blank PVDF discs treated in the same manner. Approximately $1.5 \mathrm{mg}$ are added per disc as a result of the biomimetic polymerization (average mass of "blank" PDVF disc $36.87 \pm 0.38 \mathrm{mg}$, average mass of synthetic-eumelanin-coated disc $38.40 \pm 0.40 \mathrm{mg}$ ).

2.2. Hair-Extract-Coated Discs. The extraction of melanin from human hair via an acid-base method [26, 27], described in detail below, follows the procedure of Haywood et al. with a wash/precipitation sequence modified from Liu et al. to include a step of removal of endogenous metal ions. The presence of extracted melanin throughout the procedure and its reduction following deposition on PVDF was verified by spectroscopic comparison with synthetic eumelanin standards $[25,26]$.

Five grams of human hair produce 40 coated discs by the following procedure. Black (Indian) hair $(5 \mathrm{~g})$ cut in $\sim 5 \mathrm{~mm}$ pieces is added to $250 \mathrm{~mL} 1 \mathrm{M} \mathrm{NaOH}$ (aq.) in a $1 \mathrm{~L}$ beaker at $90^{\circ} \mathrm{C}$, and the mixture is stirred for 10 minutes at $90^{\circ} \mathrm{C}$. The beaker is cooled on ice, and the total volume is returned to $250 \mathrm{~mL}$ by adding water. The mixture is centrifuged at $650 \mathrm{~g}$ for $5 \mathrm{~min}$. The supernatant is transferred to new centrifuge vessels and adjusted to $\mathrm{pH} \leq 3$ by addition of con. $\mathrm{HCl}$, inducing precipitation. The precipitate is collected by centrifugation at $14680 \mathrm{~g}$ for $10 \mathrm{~min}$. The supernatant is discarded and the precipitate is resuspended in $200 \mathrm{~mL}$ sodium phosphate buffer $(50 \mathrm{mM}, \mathrm{pH} 4.50)$. The $\mathrm{pH}$ of this suspension is adjusted to between $\mathrm{pH} 4.5$ and $\mathrm{pH} 5.0$ by addition of $3 \mathrm{M} \mathrm{NaOH}$. The suspension is mixed thoroughly, then centrifuged at $14680 \mathrm{~g}$ for $10 \mathrm{~min}$. The supernatant is discarded and the precipitate is resuspended in $200 \mathrm{~mL}$ sodium ethylenediaminetetraacetic acid buffer $\left(\mathrm{Na}_{2} \mathrm{EDTA}, 100 \mathrm{mM}\right.$, $\mathrm{pH}$ 4.50). After thorough mixing, the suspension is centrifuged at $14680 \mathrm{~g}$ for $10 \mathrm{~min}$, and then the supernatant is discarded. The precipitate is resuspended in $200 \mathrm{~mL}$ sodium phosphate buffer (50 mM, pH 4.50), mixed thoroughly, and then the suspension is centrifuged at $14680 \mathrm{~g}$ for $10 \mathrm{~min}$. After discarding the supernatant, the precipitate is resuspended in $152 \mathrm{~mL}$ sodium phosphate buffer $(50 \mathrm{mM}, \mathrm{pH}$ 4.50 ) and mixed thoroughly. Forty $2.5 \mathrm{~cm}$ PVDF discs are shaken in $\mathrm{MeOH}$ for $\sim 1 \mathrm{~min}$, followed by two water washes (up to 6 discs per $50 \mathrm{~mL} \mathrm{H}_{2} \mathrm{O}, 5 \mathrm{~min}$ each). The $152 \mathrm{~mL}$ melanin suspension in $\mathrm{pH} 4.50$ phosphate buffer is adjusted to $\mathrm{pH} 2.20( \pm 0.05)$ and distributed to 4 widemouth glass jars, $38 \mathrm{~mL}$ per jar. $12.667 \mathrm{~mL}$ of formamide (to $25 \% \mathrm{v} / \mathrm{v}, 50.667 \mathrm{~mL}$ total volume) is added to each jar, followed by 10 washed PVDF discs. The jars are shaken at $250 \mathrm{rpm}$ for $\sim 23$ hours at room temperature, during which time melanin deposits onto the PVDF discs from the $1: 3$ formamide: phosphate buffer $(50 \mathrm{mM}, \mathrm{pH} 2.20)$ suspension, forming a macroscopically spotty coating. Hair-extractcoated discs are stored immersed in water, in the dark at room temperature.

To determine the amount of hair extract per disc, $\geq 10$ discs from different depositions were stored in a dessicator until dryness and compared to blank PVDF discs treated in the same manner. Approximately $3 \mathrm{mg}$ are added per disc as a result of the hair extract deposition (average mass of "blank" PDVF disc $36.87 \pm 0.38 \mathrm{mg}$, average mass of hair-extractcoated disc $40.03 \pm 0.52 \mathrm{mg}$ ).

2.3. Metal Ion-Binding Experiments. Each titration includes 10 concentrations of the nitrate salts of $\mathrm{Pb}^{2+}(15.1 \mu \mathrm{M}$ to $2.265 \mathrm{mM}), \mathrm{Cu}^{2+}(21.5 \mu \mathrm{M}$ to $3.221 \mathrm{mM}), \mathrm{Cd}^{2+}(16.2 \mu \mathrm{M}$ to $3.240 \mathrm{mM})$, or $\mathrm{Zn}^{2+}(33.6 \mu \mathrm{M}$ to $6.720 \mathrm{mM})$. $\mathrm{Pb}^{2+}$ solutions are prepared from $\mathrm{Pb}\left(\mathrm{NO}_{3}\right)_{2}$ in pure $\mathrm{H}_{2} \mathrm{O}$ ( $\mathrm{pH}$ uncorrected) or in $50 \mathrm{mM} \mathrm{NaNO}_{3}$ (aq.), with the final $\mathrm{pH}$ for each concentration adjusted to $\mathrm{pH} 4.00,4.75$, or $5.50 . \mathrm{Cu}^{2+}, \mathrm{Cd}^{2+}$, and $\mathrm{Zn}^{2+}$ solutions are prepared from $\mathrm{Cu}\left(\mathrm{NO}_{3}\right)_{2} \cdot 2.5 \mathrm{H}_{2} \mathrm{O}$, $\mathrm{Cd}\left(\mathrm{NO}_{3}\right)_{2} \cdot 4 \mathrm{H}_{2} \mathrm{O}$, and $\mathrm{Zn}\left(\mathrm{NO}_{3}\right)_{2} \cdot 6 \mathrm{H}_{2} \mathrm{O}$, respectively, in $50 \mathrm{mM} \mathrm{NaNO}_{3}$ (aq.) with the final $\mathrm{pH}$ for each concentration adjusted to $\mathrm{pH} 4.75$.

Synthetic-eumelanin- and hair-extract-coated discs are washed twice in water (6 discs per $50 \mathrm{~mL} \mathrm{H}_{2} \mathrm{O}, 5$ min each). Uncoated, blank PVDF discs are shaken in $\mathrm{MeOH}$ for $1 \mathrm{~min}$, followed by two water washes ( 6 discs per $50 \mathrm{~mL} \mathrm{H}_{2} \mathrm{O}, 5 \mathrm{~min}$ each). Using six-well polystyrene plates, a single disc is added 


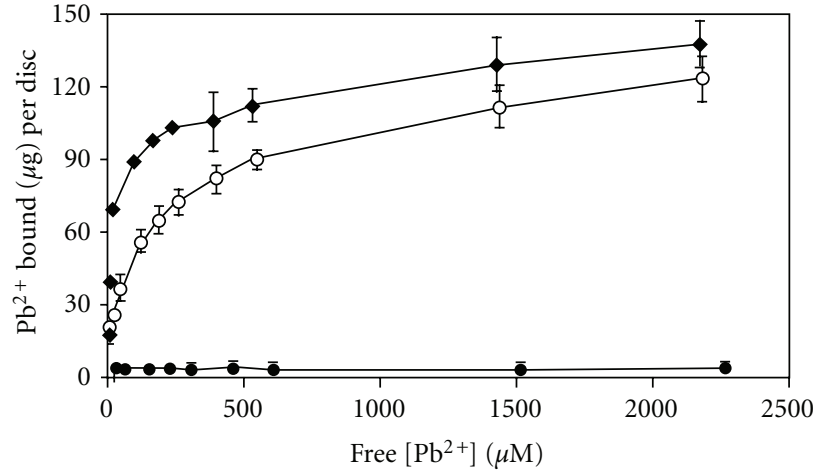

- Synthetic eumelanin

- Hair extract

- Blank PVDF

(a)

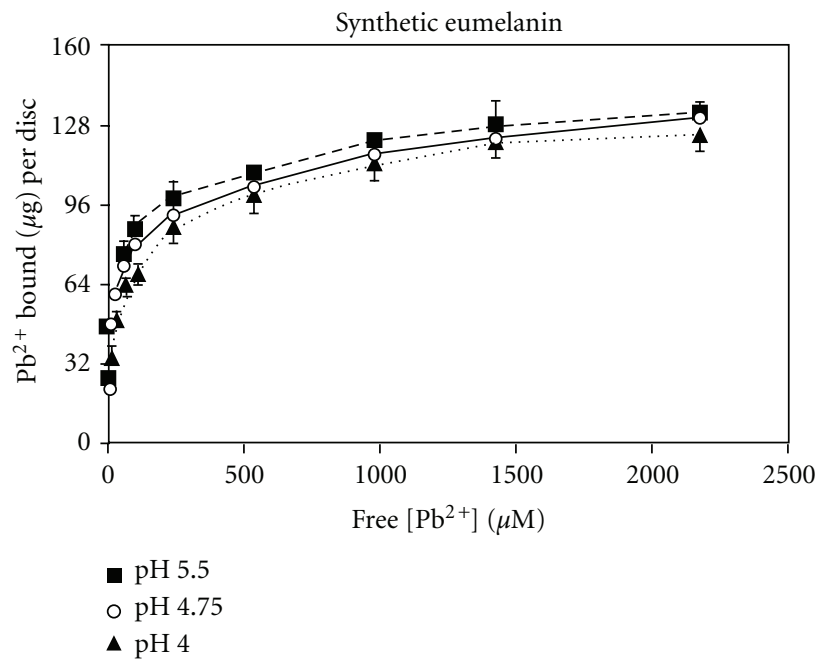

(c)

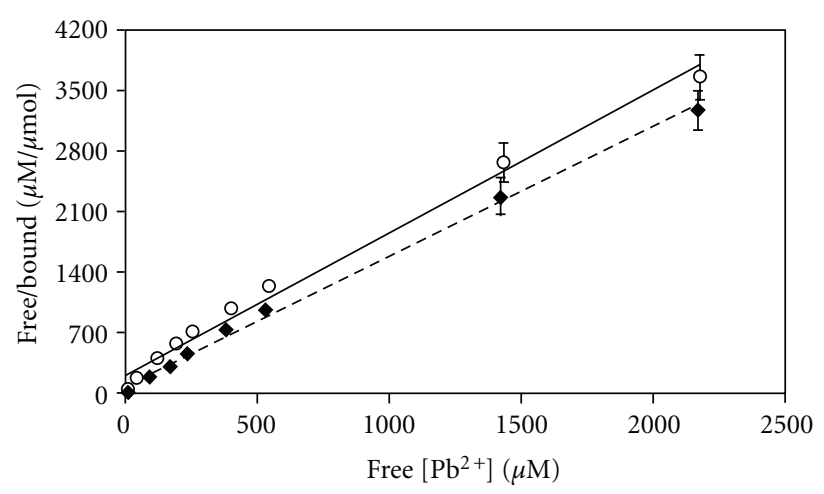

- Synthetic eumelanin

○ Hair extract

(b)

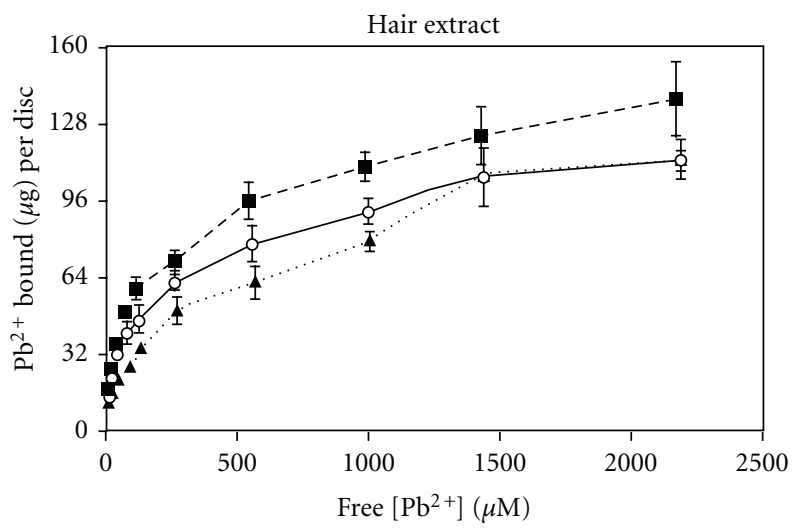

a $\mathrm{pH} 5.5$

○ $\mathrm{pH} 4.75$

$\Delta \mathrm{pH} 4$

Figure 2: (a) Binding isotherms of $\mathrm{Pb}^{2+}$ ions to synthetic-eumelanin-coated discs, hair-extract-coated discs, and blank PVDF discs; $\mathrm{pH}$ uncorrected titrations of $\mathrm{Pb}\left(\mathrm{NO}_{3}\right)_{2}$ in $\mathrm{H}_{2} \mathrm{O}$. (b) Linearized Langmuir isotherm representation of the data for synthetic-eumelanin- and hairextracted-coated discs in (a), $R^{2} \geq 0.98$. (c) Binding isotherms to $\mathrm{Pb}^{2+}$ ions to synthetic-eumelanin-coated discs; titrations of $\mathrm{Pb}\left(\mathrm{NO}_{3}\right)_{2}$ in $50 \mathrm{mM} \mathrm{NaNO}_{3}$ (aq.) at initial pH 5.50, 4.75, and 4.00. (d) Binding isotherms to $\mathrm{Pb}^{2+}$ ions to hair-extract-coated discs; titrations of $\mathrm{Pb}\left(\mathrm{NO}_{3}\right)_{2}$ in $50 \mathrm{mM} \mathrm{NaNO}_{3}$ (aq.) at initial pH 5.50, 4.75, and 4.00. (a-d) Data are average values from at least three independent titrations, each with different discs; error bars represent one standard deviation.

to $7 \mathrm{~mL}$ per well of a metal ion-containing solution. The sixwell plates are covered with tinfoil and shaken at room temperature for $\sim 22 \mathrm{hrs}$. At the end of this equilibration, discs are removed and washed individually $\left(25 \mathrm{~mL} \mathrm{H}_{2} \mathrm{O}, 5 \mathrm{~min}\right.$, $2 \mathrm{x})$. A single disc is added to $7 \mathrm{~mL}$ of EDTA solution (100 $\mathrm{mM} \mathrm{Na}_{2}$ EDTA, $\mathrm{pH} 4.50$ ) per well in six-well polystyrene plates. The six-well plates are covered with tinfoil and shaken at room temperature for $30 \mathrm{~min}$. The discs are removed and the EDTA solutions were analyzed using atomic absorption spectroscopy in flame mode. Lead samples were analyzed using a Perkin-Elmer 1100B atomic absorption spectrometer (air-acetylene flame, $0.7 \mathrm{~nm}$ slot width, hollow cathode lamp, $283.3 \mathrm{~nm}$ ). A Perkin-Elmer AAnalyst 700 atomic absorption spectrometer was used to analyze copper (air-acetylene flame, $0.7 \mathrm{~nm}$ slot width, hollow cathode lamp, $324.8 \mathrm{~nm}$ ), cadmium (air-acetylene flame, $0.7 \mathrm{~nm}$ slot width, hollow cathode lamp, $228.8 \mathrm{~nm}$ ), and zinc (air-acetylene flame,
$0.7 \mathrm{~nm}$ slot width, hollow cathode lamp, $213.9 \mathrm{~nm})$. Metal ion concentrations (in $\mu \mathrm{g} / \mathrm{mL}$ ) were determined with respect to a standard curve generated during the same session. The total amount of metal ion per EDTA solution $(\mu \mathrm{g} / \mathrm{mL} \times 7 \mathrm{~mL}$ volume) is taken to be the total amount $(\mu \mathrm{g})$ of metal ion bound per disc. The data shown in Figures 2 and 3 and Tables 1, 2, and 3 represent average values from at least three independent titrations, each with different discs.

\section{Results and Discussion}

Our procedure for investigating melanin-metal ion interactions on solid support begins with the formation of a melanin-based coating on discs of the hydrophobic polymer polyvinylidene di-fluoride (PVDF). The coated discs are then allowed to equilibrate with varying concentrations of the target ion for 22 hours, washed, and immersed in a solution 


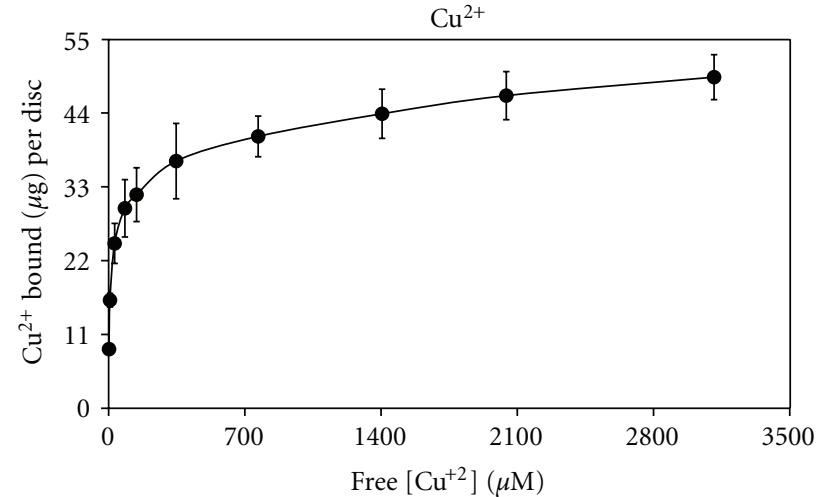

- Synthetic eumelanin

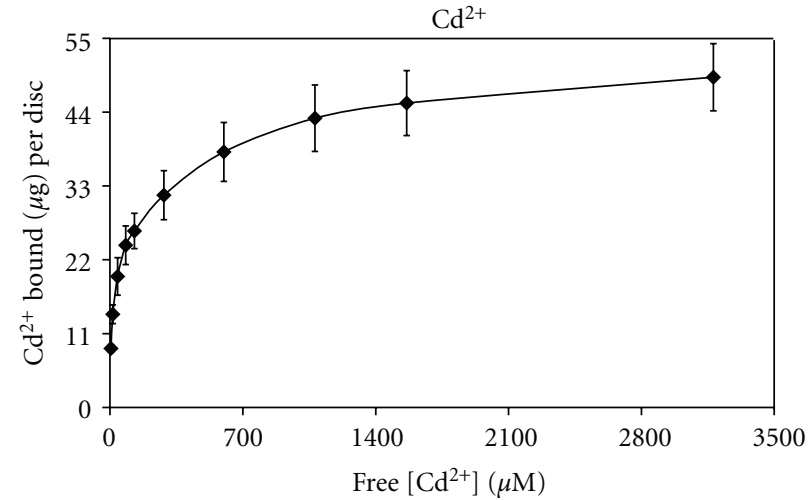

- Synthetic eumelanin

(b)

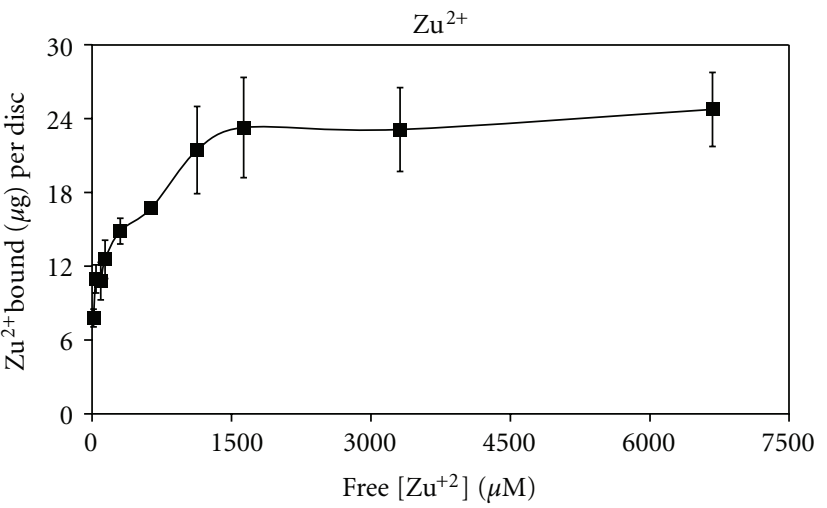

- Synthetic eumelanin

(c)

Figure 3: (a) Binding isotherm of $\mathrm{Cu}^{2+}$ ions to synthetic-eumelanin-coated discs; titration of $\mathrm{Cu}\left(\mathrm{NO}_{3}\right)_{2} \cdot 2.5 \mathrm{H}_{2} \mathrm{O}$ in $50 \mathrm{mM} \mathrm{NaNO}$ (aq.) at initial $\mathrm{pH}$ 4.75. (b) Binding isotherm of $\mathrm{Cd}^{2+}$ ions to synthetic-eumelanin-coated discs; titration of $\mathrm{Cd}\left(\mathrm{NO}_{3}\right)_{2} \cdot 4 \mathrm{H}_{2} \mathrm{O}$ in $50 \mathrm{mM}$ $\mathrm{NaNO}_{3}$ (aq.) at initial $\mathrm{pH}$ 4.75. (c) Binding isotherm of $\mathrm{Zn}^{2+}$ ions to synthetic-eumelanin-coated discs; titration of $\mathrm{Zn}\left(\mathrm{NO}_{3}\right)_{2} \cdot 6 \mathrm{H}_{2} \mathrm{O}$ in $50 \mathrm{mM} \mathrm{NaNO}_{3}$ (aq.) at initial $\mathrm{pH}$ 4.75. (a-c) Data are average values from at least three independent titrations, each with different discs; error bars represent one standard deviation.

TABLE 1: Lead-binding parameters.

\begin{tabular}{|c|c|c|}
\hline \multicolumn{3}{|c|}{ Synthetic-eumelanin-coated discs } \\
\hline $\mathrm{pH}^{\mathrm{a}}$ & $K_{L}\left(\mathrm{M}^{-1}\right)^{\mathrm{b}}$ & $\begin{array}{l}\text { Capacity } \\
\mu \mathrm{g} / \text { disc }^{\mathrm{b}}\end{array}$ \\
\hline Uncorrected & $1.74( \pm 0.12) \cdot 10^{4}$ & $137.8 \pm 10.1$ \\
\hline 5.50 & $2.21( \pm 0.22) \cdot 10^{4}$ & $133.0 \pm 4.2$ \\
\hline 4.75 & $1.83( \pm 0.02) \cdot 10^{4}$ & $130.3 \pm 5.5$ \\
\hline 4.00 & $1.40( \pm 0.15) \cdot 10^{4}$ & $119.1 \pm 6.5$ \\
\hline \multicolumn{3}{|c|}{ Hair-extract-coated discs } \\
\hline $\mathrm{pH}^{\mathrm{a}}$ & $K_{L}\left(\mathrm{M}^{-1}\right)^{\mathrm{b}}$ & $\begin{array}{l}\text { Capacity } \\
\mu \mathrm{g} / \text { disc }^{\mathrm{b}}\end{array}$ \\
\hline Uncorrected & $7.58( \pm 0.39) \cdot 10^{3}$ & $126.1 \pm 9.5$ \\
\hline 5.50 & $7.04( \pm 0.56) \cdot 10^{3}$ & $139.1 \pm 14.7$ \\
\hline 4.75 & $6.74( \pm 1.04) \cdot 10^{3}$ & $115.6 \pm 5.4$ \\
\hline $4.00^{c}$ & $3.40( \pm 0.20) \cdot 10^{3}$ & $110.5 \pm 9.3$ \\
\hline
\end{tabular}

${ }^{a}$ Uncorrected titrations are $\mathrm{Pb}\left(\mathrm{NO}_{3}\right)_{2}$ in $\mathrm{H}_{2} \mathrm{O}$, other titrations are $\mathrm{Pb}\left(\mathrm{NO}_{3}\right)_{2}$ in $50 \mathrm{mM} \mathrm{NaNO}_{3}$ with the initial $\mathrm{pH}$ adjusted as shown.

${ }^{b}$ Values calculated from linearized Langmuir isotherms from at least three independent titrations with different discs; standard deviations shown.

${ }^{c}$ Linearized Langmuir isotherm $R^{2} \geq 0.96$, all others $R^{2} \geq 0.98$. 
TABLE 2: Percentage of $\mathrm{Pb}^{2+}$ bound at equilibrium.

\begin{tabular}{|c|c|c|c|c|c|c|}
\hline \multirow{2}{*}{ Initial $\left[\mathrm{Pb}^{2+}\right]$} & \multicolumn{3}{|c|}{ Synthetic eumelanin $^{a}$} & \multicolumn{3}{|c|}{ Hair extract ${ }^{\mathrm{a}}$} \\
\hline & pH 5.50 & $\mathrm{pH} 4.75$ & $\mathrm{pH} 4.00$ & pH 5.50 & $\mathrm{pH} 4.75$ & $\mathrm{pH} 4.00$ \\
\hline $15.1 \mu \mathrm{M}$ & $>95 \%$ & $>95 \%$ & $>95 \%$ & $82.2 \%$ & $68.2 \%$ & $42.6 \%$ \\
\hline $30.2 \mu \mathrm{M}$ & $>95 \%$ & $>95 \%$ & $73.3 \%$ & $58.6 \%$ & $49.7 \%$ & $29.4 \%$ \\
\hline $60.4 \mu \mathrm{M}$ & $68.8 \%$ & $68.7 \%$ & $52.6 \%$ & $41.2 \%$ & $36.1 \%$ & $22.5 \%$ \\
\hline $105.7 \mu \mathrm{M}$ & $49.8 \%$ & $46.7 \%$ & $38.7 \%$ & $32.1 \%$ & $26.7 \%$ & $16.7 \%$ \\
\hline $151.0 \mu \mathrm{M}$ & $39.3 \%$ & $36.8 \%$ & $29.4 \%$ & $26.9 \%$ & $21.0 \%$ & $14.9 \%$ \\
\hline $302.0 \mu \mathrm{M}$ & $22.4 \%$ & $21.0 \%$ & $18.3 \%$ & $16.1 \%$ & $14.1 \%$ & $10.0 \%$ \\
\hline $604.0 \mu \mathrm{M}$ & $12.4 \%$ & $11.8 \%$ & $10.6 \%$ & $10.8 \%$ & $8.8 \%$ & $6.3 \%$ \\
\hline $1057.0 \mu \mathrm{M}$ & $8.0 \%$ & $7.6 \%$ & $6.7 \%$ & $7.2 \%$ & $5.7 \%$ & $4.9 \%$ \\
\hline $1510.0 \mu \mathrm{M}$ & $5.6 \%$ & $5.6 \%$ & $5.2 \%$ & $5.6 \%$ & $4.8 \%$ & $4.3 \%$ \\
\hline $2265.0 \mu \mathrm{M}$ & $4.0 \%$ & $4.0 \%$ & $3.6 \%$ & $4.2 \%$ & $3.4 \%$ & $3.2 \%$ \\
\hline
\end{tabular}

${ }^{a}$ Percentage of $\mathrm{Pb}^{2+}$ bound at equilibrium for each initial concentration from the titrations shown in Figures 2(c) and 2(d).

TABLE 3: Binding parameters of synthetic-eumelanin-coated discs with different metal ions.

\begin{tabular}{|c|c|c|c|c|}
\hline & $K_{L}\left(\mathrm{M}^{-1}\right)^{\mathrm{a}}$ & $\begin{array}{l}\text { Capacity } \\
\mu \mathrm{g} / \text { disc }^{\mathrm{a}}\end{array}$ & $\begin{array}{l}\text { Capacity } \\
\text { nmol/disc }^{\text {a }}\end{array}$ & $\begin{array}{l}\text { Highest \% bound } \\
\left(\text { initial }\left[\mathrm{M}^{2+}\right]\right)^{\mathrm{b}}\end{array}$ \\
\hline $\mathrm{Pb}^{2+\mathrm{c}}$ & $1.83( \pm 0.02) \cdot 10^{4}$ & $130.3( \pm 5.5)$ & $629( \pm 27)$ & $>95 \%(15.1-30.2 \mu \mathrm{M})$ \\
\hline $\mathrm{Cu}^{2+}$ & $1.41( \pm 0.33) \cdot 10^{4}$ & $49.0( \pm 3.2)$ & $771( \pm 51)$ & $92.3 \%(21.5 \mu \mathrm{M})$ \\
\hline $\mathrm{Cd}^{2+}$ & $9.70( \pm 0.74) \cdot 10^{3}$ & $49.8( \pm 5.0)$ & $443( \pm 45)$ & $68.9 \%(16.2 \mu \mathrm{M})$ \\
\hline $\mathrm{Zn}^{2+}$ & $6.44( \pm 0.19) \cdot 10^{3}$ & $25.0( \pm 3.2)$ & $383( \pm 49)$ & $47.9 \%(33.6 \mu \mathrm{M})$ \\
\hline
\end{tabular}

${ }^{\mathrm{a}}$ Titrations in $50 \mathrm{mM} \mathrm{NaNO}_{3}$, initial $\mathrm{pH} 4.75$, binding isotherms are shown in Figures 2(c) and 3. Values calculated from linearized Langmuir isotherms $\left(R^{2} \geq 0.99\right)$ from at least three independent titrations with different discs; standard deviations shown.

${ }^{\mathrm{b}}$ For each metal ion, the highest observed percentage bound at equilibrium is listed, with the initial concentration where this occurs shown in parentheses.

${ }^{c}$ Values for $\mathrm{Pb}^{2+}$ are repeated from Tables 1 and 2.

containing the chelating agent EDTA for 30 minutes. The metal ion content of this solution is then analyzed by atomic absorption spectroscopy (flame mode). Preliminary kinetic investigations show that 22 hours is more than sufficient for equilibration. Similarly, 30 minutes in a $100 \mathrm{mM} \mathrm{Na}{ }_{2}$ EDTA solution ( $\mathrm{pH} 4.50)$ was sufficient for metal ion extraction, in that further washes did not yield additional removal of metal ions. This does not rule out the possibility of an extremely tight-binding fraction, and weakly bound ions may be lost in the washing steps, such that the procedure may underestimate the total amount of metal ions bound. However, direct measurement of the decrease in metal ion concentration in the equilibration solutions agrees well with the amount recovered in the EDTA washes (data not shown).

Commercially available PVDF membranes (BioTrace, Pall) with 40 micron pores are typically used for bioanalytical applications such as Western blots. PVDF has been previously used as solid-support for metal ion-binding polymer membranes [37] and was chosen for use here because it displays little to no binding to lead ions on its own (Figure 2(a)). Preparation of synthetic eumelanin and deposition onto PVDF was accomplished in a single overnight step. Initiating the biomimetic tyrosinase-catalyzed oxidative polymerization of L-dopa [22] in the presence of $2.5 \mathrm{~cm}$ PVDF discs and allowing the reaction to proceed for $\sim 22 \mathrm{hrs}$ at room temperature while shaking at a rate fast enough $(250 \mathrm{rpm})$ to avoid settling or self-aggregation of the hydrophobic discs provides a black synthetic eumelanin coating (Figure 1(b), see Section 2 for detailed procedure). The average mass added per disc during this biomimetic polymerization is on the order of $1.5 \mathrm{mg}$. Compared to eumelanin samples from natural sources such as Sepia ink, synthetic eumelanin materials produced from L-dopa/tyrosinase tend to have a lower DHICA : DHI ratio (i.e., fewer carboxylic acids) and tend to be more amorphous [34].

PVDF discs can also be coated with melanin from human hair (see Section 2 for detailed procedure). Melanin in hair is a mixture of eumelanin and pheomelanin; black hair, used in this study, primarily contains eumelanin [25]. A straightforward acid/base extraction procedure $[26,27]$ was used, including a short, high temperature, basic heating step $\left(1 \mathrm{M} \mathrm{NaOH}, 90^{\circ} \mathrm{C}, 10 \mathrm{~min}\right)$, which has been shown to reduce melanin degradation for black hair samples [26] and an EDTA wash to remove endogenously bound metal ions. Following extraction from hair, melanin deposits onto PVDF discs from an acidic 25\% formamide solution forming a macroscopically spotty coating. The average mass added per disc as a result of this deposition is on the order of $3 \mathrm{mg}$, which represents a $2.4 \%$ recovery of the mass of hair used. This hair extract coating is likely not completely free of keratin —also a metal-binding agent-and the melanin may experience some degradation, which results in increased carboxylic acid content [27]. Both the hair extract and synthetic eumelanin coatings are stable to shaking and storage in aqueous solutions, without loss of material from the support over the course of shaking for $22 \mathrm{hrs}$ during binding experiments or at least two weeks of storage in water (hair-extract-coated discs) or $50 \mathrm{mM}$ sodium phosphate 
buffer, pH 7.0 (synthetic-eumelanin-coated discs). If the coated discs are stored at room temperature in aqueous solution on the time-scale of months, some leaching into the solution is observed.

The binding assay outlined above and described in detail in Section 2 was developed with $\mathrm{Pb}^{2+}$ as the initial target ion (Figure 2 and Tables 1 and 2). Coated and blank PVDF discs were immersed in aqueous lead nitrate solutions with concentrations ranging from $15.1 \mu \mathrm{M}$ to $2.265 \mathrm{mM}$. Following a $22 \mathrm{hr}$ equilibration, the discs were washed in pure water and then exposed to an EDTA solution $\left(100 \mathrm{mM} \mathrm{Na}{ }_{2}\right.$ EDTA, $\mathrm{pH}$ 4.50) for 30 minutes. Lead ions that bound to the discs were extracted into the EDTA solution, which is then quantified by atomic absorption spectroscopy (flame mode, see Section 2). As shown in Figure 2(a), a plot of $\mu \mathrm{g} \mathrm{Pb}^{2+}$ bound per disc versus free $\left[\mathrm{Pb}^{2+}\right]$, the coated discs show significant binding compared to the negligible results for the blank discs. In our first titrations (Figures 2(a) and 2(b), designated " $\mathrm{pH}$ uncorrected," the equilibration solutions contained only $\mathrm{Pb}\left(\mathrm{NO}_{3}\right)_{2}$ in pure water, such that the ionic strength and initial $\mathrm{pH}$ of these solutions varies with the different $\mathrm{Pb}^{2+}$ concentrations tested $(4.75<\mathrm{pH}<5.50)$. Titrations were also carried out in $50 \mathrm{mM} \mathrm{NaNO}_{3}$ with varying $\mathrm{Pb}\left(\mathrm{NO}_{3}\right)_{2}$ concentrations with all solutions in a given titration adjusted to the same initial $\mathrm{pH}$ value (Figures 2(c) and 2(d), Tables 1 and 2). Solutions were set to an initial $\mathrm{pH}$ of $5.50,4.75$, or 4.00 , values which span the initial $\mathrm{pH}$ range of the uncorrected titrations and extend to $\mathrm{pH}$ 4.00 on the acidic side, a value that is commonly tested in lead-binding experiments $[30,31]$. Seven of the eight titrations are extremely good fits $\left(R^{2} \geq 0.98\right)$ for the Langmuir surface-binding model [38] (see linearized Langmuir isotherm, Figure 2(b), and Table 1). In the $\mathrm{pH}$ uncorrected titrations (Figures 2(a) and 2(b) and Table 1), the syntheticeumelanin-coated discs display a Langmuir affinity $\left(K_{L}\right)$ of $1.74 \cdot 10^{4} \mathrm{M}^{-1}$ and a capacity of $138 \mu \mathrm{g} \mathrm{Pb}^{2+}$ bound per disc. Amberlite IR-120, a commercial ion-exchange resin, has a similar affinity for lead ions $\left(K_{L}=1.2 \cdot 10^{4}\right)$ [30]. The hairextract-coated discs display a $\sim 2$-fold-lower Langmuir affinity of $7.58 \cdot 10^{3} \mathrm{M}^{-1}$ and a slightly lower capacity of $126 \mu \mathrm{g}$ $\mathrm{Pb}^{2+}$ bound per disc.

The effect of varying the initial $\mathrm{pH}$ of the equilibration solutions in the tested range is relatively modest (Figures 2(c) and 2(d) and Tables 1 and 2). The affinity and capacity of the synthetic-eumelanin-coated discs in the $\mathrm{pH} 4.00$ titration are $63 \%$ and $86 \%$, respectively, of these values in the $\mathrm{pH} 5.50$ titration. For the hair extract coating in the $\mathrm{pH} 4.00$ titration, the affinity and capacity are $45 \%$ and $80 \%$, respectively, of these values in the $\mathrm{pH} 5.50$ titration. Table 2 shows the percentage of $\mathrm{Pb}^{2+}$ bound at equilibrium for each point of these titrations; variation with $\mathrm{pH}$ is particularly apparent for the hair-extract-coated discs. At initial concentrations up to $30.2 \mu \mathrm{M}$ for the $\mathrm{pH} 4.75$ and 5.50 titrations, or $15.1 \mu \mathrm{M}$ for the $\mathrm{pH} 4.00$ titration, the synthetic eumelanin coating bound $>95 \%$ of the $\mathrm{Pb}^{2+}$ originally in solution. Recently, Chen et al. reported that melanin extracted from squid ink is able to bind $95 \%$ of the $\mathrm{Pb}^{2+}$ initially present in solutions of $500 \mu \mathrm{M}$ to $2.0 \mathrm{mM}$ [18]. However, it is difficult to directly compare these results to the data presented in Table 2 because of large differences in the amounts of material used (200 mg versus $1.5-3.0 \mathrm{mg}$ coating per disc). Au and Potts compared the binding efficiency of synthetic eumelanin and melanin extracted from three different regions of the bovine eye (all as free suspensions), for a variety of metal ions at the same initial concentration $(1.67 \mathrm{mM})[36] . \mathrm{Pb}^{2+}$ was one of the metal ions with the highest percent bound, and the synthetic eumelanin sample had intermediate efficiency between the different natural samples; melanin extracted from the choroid was the strongest binder [36]. Here, melanin extracted from human hair is less efficient than the synthetic coating (Table 2). An enzymatic extraction procedure [27] and/or alternate deposition conditions may allow us to utilize the renewable resource of human hair for more efficient leadbinding melanin-based coatings than this first generation.

The Langmuir affinity constants (Table 1) for the hairextract- and synthetic-coated discs are within the range of values of affinity constants $\left(10^{3}\right.$ to $\left.10^{7} \mathrm{M}^{-1}\right)$ obtained by a variety of methods for different metal ions with synthetic and natural melanin samples $[7,38]$. Earlier reports have suggested that natural and synthetic eumelanin samples have a high affinity for $\mathrm{Pb}^{2+}$ compared to other metal ions $[35,36]$, but affinity constants were not established in these studies, and until recently [18], current studies have generally not included lead. Given the known heterogeneity of both the natural and synthetic samples, the Langmuir affinity values reported here presumably represent an aggregate affinity rather than a microscopic per site affinity. On a molecular level, the catechol-like oxygens, carboxylic acids, the indole nitrogens, and the indole $\pi$ electron density all potentially play some role in binding. In a recent study using melanin from squid ink, Chen et al. saw evidence of involvement of both the catechol and carboxylate functionalities in lead binding [18]. Affinity constants were not determined in that study but it was found that lead binding was more resistant than cadmium binding to competition with salts although this could be due differing binding modes as well as differing affinities [18].

Although the PVDF support shows little to no affinity for lead ions on its own, the structure of the support likely influences both the number and distribution of available binding sites compared to other presentations. Nevertheless, for comparison with other systems we considered binding as a function of the mass of the coating. At the maximum capacities, the synthetic eumelanin coating binds $\sim 9 \%$ of its mass in $\mathrm{Pb}^{2+}(138 \mu \mathrm{g} / 1.5 \mathrm{mg})$, while the hair extract coating binds $\sim 4.5 \%$ of its mass in $\mathrm{Pb}^{2+}(139 \mu \mathrm{g} / 3 \mathrm{mg})$. These values, which equate to $0.44 \mathrm{mmol}\left(\mathrm{Pb}^{2+}\right) / \mathrm{g}$ (coating) and $0.22 \mathrm{mmol} / \mathrm{g}$ for the synthetic eumelanin and hair extract, respectively, should be considered approximate, because of uncertainty in the average mass of the coating. Nevertheless, they are within the range of reported capacities for a variety of natural and synthetic melanin samples with different metal ions [7] and are at the higher end of heavy metal capacities for a variety of biosorbents [32]. Melanin extracted from squid ink was able to bind $13.5 \%$ of its mass in $\mathrm{Pb}^{2+}$ at capacity $(0.65 \mathrm{mmol} / \mathrm{g})$ [18].

To begin to assess the selectivity of melanin-based coatings for $\mathrm{Pb}^{2+}$ and probe the generality of the binding assay, 
titrations of the nitrate salts of copper $\left(\mathrm{Cu}^{2+}\right)$, cadmium $\left(\mathrm{Cd}^{2+}\right)$, and zinc $\left(\mathrm{Zn}^{2+}\right)$ were performed with synthetic-eumelanin-coated discs (Figure 3 and Table 3 ). Ten concentrations of each metal ion in $50 \mathrm{mM} \mathrm{NaNO}_{3}$ (aq.), initial $\mathrm{pH}$ adjusted to $\mathrm{pH} 4.75$, were used, for comparison with the $\mathrm{Pb}^{2+}$ results. All three titrations were extremely good fits $\left(R^{2} \geq 0.99\right)$ for the Langmuir model yielding $K_{L}$ values of $1.41 \cdot 10^{4} \mathrm{M}^{-1}$ for $\mathrm{Cu}^{2+}, 9.70 \cdot 10^{3} \mathrm{M}^{-1}$ for $\mathrm{Cd}^{2+}$, and $6.44 \cdot 10^{3} \mathrm{M}^{-1}$ for $\mathrm{Zn}^{2+}$. Thus, under the conditions tested, the Langmuir affinities for $\mathrm{Zn}^{2+}, \mathrm{Cd}^{2+}$, and $\mathrm{Cu}^{2+}$ were $35 \%, 53 \%$, and $77 \%$, respectively, of the Langmuir affinity for $\mathrm{Pb}^{2+}$. In terms of capacity, on the basis of mass bound, the discs have significantly higher capacity for lead than the other ions tested, but this is partially the result of the mass of lead itself; on per mole basis, the capacities for $\mathrm{Zn}^{2+}$ (383 nmol/disc, $\sim 0.26 \mathrm{mmol} / \mathrm{g}$ coating) and $\mathrm{Cd}^{2+}$ ( $443 \mathrm{nmol} / \mathrm{disc}, \sim 0.30 \mathrm{mmol} / \mathrm{g}$ coating) are below the capacity for $\mathrm{Pb}^{2+}(629 \mathrm{nmol} / \mathrm{disc}, \sim 0.42 \mathrm{mmol} / \mathrm{g}$ coating), while the capacity for $\mathrm{Cu}^{2+}(771 \mathrm{nmol} /$ disc, $\sim 0.51 \mathrm{mmol} / \mathrm{g}$ coating) is higher. Chen et al. found that melanin from squid ink had a higher molar capacity for $\mathrm{Cd}^{2+}(0.93 \mathrm{mmol} / \mathrm{g})$ than for $\mathrm{Pb}^{2+}$ $(0.65 \mathrm{mmol} / \mathrm{g})$ [18]. Copper and zinc are among the most studied metal ions for interactions with natural and synthetic melanin samples [7, 20,33,39]. In general $\mathrm{Cu}^{2+}$ is found to be the stronger binder, while the capacity for $\mathrm{Zn}^{2+}$ can be taken as a reflection of the DHICA content of the melanin sample [7]. For example, Sepia eumelanin has a higher capacity for $\mathrm{Zn}^{2+}(\sim 1.5 \mathrm{mmol} / \mathrm{g})$ than for $\mathrm{Cu}^{2+}(1.1 \mathrm{mmol} / \mathrm{g})$ [7], whereas the lower capacity for zinc ions here likely reflects the lower DHICA : DHI ratio in L-dopa/tyrosinase synthetic eumelanin [34]. The generally lower capacities displayed by the synthetic-eumelanin-coating compared to natural melanin samples for the four metal ions tested likely reflect differences in both the composition of the synthetic eumelanin and its presentation on PVDF.

A study by Buszman et al. comparing the binding of metal ions including $\mathrm{Cu}^{2+}, \mathrm{Cd}^{2+}$, and $\mathrm{Zn}^{2+}$ (but $\mathrm{Pb}^{2+}$ ) to a suszpension of synthetic eumelanin generated by the autoxidation of L-dopa (i.e., a different method than used here) was recently reanalyzed $[38,40]$. Fitting the data to several different models Bridelli and Crippa found the affinity order $\mathrm{Zn}^{2+}<\mathrm{Cd}^{2+}<\mathrm{Cu}^{2+}[38]$, which is the same order as observed here. In their study with bovine eye melanin and synthetic eumelanin (produced by the L-dopa/tyrosinase method) Potts and $\mathrm{Au}$ found that $\mathrm{Zn}^{2+}$ had lower binding efficiency than $\mathrm{Pb}^{2+}$ and $\mathrm{Cu}^{2+}$, which had had similar binding efficiency $\left(\mathrm{Cd}^{2+}\right.$ was not tested) [36]. Using a competitive binding assay against the nitrogen di-cation paraquat, Larsson and Tjalve found that $\mathrm{Pb}^{2+}$ was slightly more competitive than $\mathrm{Cu}^{2+}$ and that $\mathrm{Pb}^{2+}, \mathrm{Cu}^{2+}, \mathrm{La}^{3+}$, and $\mathrm{Gd}^{3+}$ were the most competitive of eighteen metal ions tested for bovine eye melanin (however, $\mathrm{Zn}^{2+}$ and $\mathrm{Cd}^{2+}$ were not tested) [35]. These authors tested a more limited subset of metal ions with synthetic eumelanin produced by the L-dopa/tyrosinase method; $\mathrm{Pb}^{2+}$ was again slightly less competitive than $\mathrm{La}^{3+}$ and more competitive than other metal ions tested $\left(\mathrm{Cu}^{2+}\right.$ was not tested with the synthetic sample) [35]. Overall, the results for the synthetic eumelanin coated discs with the four metal ions tested here (Table 2) are consistent with affinity trends in the literature and add to the earlier findings that eumelanin binds $\mathrm{Pb}^{2+}$ strongly compared to other metal ions, with affinity similar to (or, under the conditions tested here, slightly higher than) its affinity for $\mathrm{Cu}^{2+}$. In this context, it is interesting to note that, compared to the presence of these metals in the surrounding tissue, neuromelanin concentrates lead to a much greater extent than copper [13].

\section{Conclusions}

Melanins have many fascinating chemical properties in addition to their roles as biological pigments, including molecular recognition properties that are potentially advantageous for water purification applications. In this study we have developed a procedure for investigating melaninmetal ion interactions on solid support, with lead as the initial target. Melanin-based coatings derived by extraction of melanin from human hair and the biomimetic tyrosinasecatalyzed oxidation of $\mathrm{L}$-dopa were shown to bind $\mathrm{Pb}^{2+}$ ions with reasonable affinity and high capacity, with the synthetic eumelanin coating binding up to $\sim 9 \%$ of its mass in lead. Considered by mass bound, the synthetic-eumelanin-coated discs have a much higher capacity for $\mathrm{Pb}^{2+}$ than for $\mathrm{Cu}^{2+}$, $\mathrm{Cd}^{2+}$, or $\mathrm{Zn}^{2+}$; however, on a per mole basis the capacity for $\mathrm{Cu}^{2+}$ is slightly higher than for $\mathrm{Pb}^{2+}$. The affinity of the synthetic eumelanin coating for $\mathrm{Pb}^{2+}$ is slightly higher than $\mathrm{Cu}^{2+}$ and higher than for $\mathrm{Zn}^{2+}$ and $\mathrm{Cd}^{2+}$. Various additives can be used to alter the composition of synthetic eumelanin polymerizations, such that the binding properties of the resulting coatings can be varied in a combinatorial fashion, potentially yielding materials with greater selectivity for lead. We are investigating other methods of isolation/deposition of natural melanin from human hair (including different color samples for varied pheomelanin content), as well as second generation synthetic coatings. Results bearing on melanin biochemistry, heavy metal toxicology, and melanin-based water purification efforts will be disclosed in due course.

\section{Acknowledgments}

Acknowledgment is made to the donors of the American Chemical Society Petroleum Research Fund for partial support of this research. The authors thank Research Corporation (Cottrell College Science Award) and Oberlin College for additional support.

\section{References}

[1] A. Huijser, A. Pezzella, and V. Sundström, "Functionality of epidermal melanin pigments: current knowledge on UVdissipative mechanisms and research perspectives," Physical Chemistry Chemical Physics, vol. 13, no. 20, pp. 9119-9127, 2011.

[2] J. D. Simon and D. N. Peles, "The red and the black," Accounts of Chemical Research, vol. 43, no. 11, pp. 1452-1460, 2010.

[3] K.-Y. Ju, Y. Lee, S. Lee, S. B. Park, and J.-K. Lee, "Bioinspired polymerization of dopamine to generate melanin-like nanoparticles having an excellent free-radical-scavenging property," Biomacromolecules, vol. 12, no. 3, pp. 625-632, 2011. 
[4] M. Arzillo, A. Pezzella, O. Crescenzi et al., "Cyclic structural motifs in 5,6-dihydroxyindole polymerization uncovered: biomimetic modular buildup of a unique five-membered macrocycle," Organic Letters, vol. 12, no. 14, pp. 3250-3253, 2010.

[5] F. Bernsmann, V. Ball, F. Addiego et al., "Dopamine-melanin film deposition depends on the used oxidant and buffer solution," Langmuir, vol. 27, no. 6, pp. 2819-2825, 2011.

[6] M. D'Ischia, A. Napolitano, A. Pezzella, P. Meredith, and T. Sarna, "Chemical and structural diversity in eumelanins: unexplored bio-optoelectronic materials," Angewandte Chemie - International Edition, vol. 48, no. 22, pp. 3914-3921, 2009.

[7] L. Hong and J. D. Simon, "Current understanding of the binding sites, capacity, affinity, and biological significance of metals in melanin," Journal of Physical Chemistry B, vol. 111, no. 28, pp. 7938-7947, 2007.

[8] P. Borghetti, A. Goldoni, C. Castellarin-Cudia et al., "Effects of potassium on the supramolecular structure and electronic properties of eumelanin thin films," Langmuir, vol. 26, no. 24, pp. 19007-19013, 2010.

[9] M. J. Hoogduijn, N. P. Smit, A. Van Der Laarse, A. F. Van Nieuwpoort, J. M. Wood, and A. J. Thody, "Melanin has a role in $\mathrm{Ca}^{2+}$ homeostasis in human melanocytes," Pigment Cell Research, vol. 16, no. 2, pp. 127-132, 2003.

[10] F. L. Meyskens and S. Yang, "Thinking about the role (Largely Ignored) of heavy metals in cancer prevention: hexavalent chromium and melanoma as a case in point," in Clinical Cancer Prevention, H.-J. Senn and F. Otto, Eds., chapter 5, pp. 65-74, Springer, Berlin, Germany, 2011.

[11] P. J. Farmer, S. Gidanian, B. Shahandeh, A. J. Di Bilio, N. Tohidian, and F. L. Meyskens, "Melanin as a target for melanoma chemotherapy: pro-oxidant effect of oxygen and metals on melanoma viability," Pigment Cell Research, vol. 16, no. 3, pp. 273-279, 2003.

[12] A. M. Snyder and J. R. Connor, "Iron, the substantia nigra and related neurological disorders," Biochimica et Biophysica Acta, vol. 1790, no. 7, pp. 606-614, 2009.

[13] L. Zecca, C. Bellei, P. Costi et al., "New melanic pigments in the human brain that accumulate in aging and block environmental toxic metals," Proceedings of the National Academy of Sciences of the United States of America, vol. 105, no. 45, pp. 17567$17572,2008$.

[14] D. J. Tobin, Ed., Hair in Toxicology: An Important Bio-Monitor, Royal Society of Chemistry, Cambridge, UK, 2005.

[15] R. A. Wogelius, P. L. Manning, H. E. Barden et al., "Trace metals as biomarkers for eumelanin pigment in the fossil record," Science, vol. 333, no. 6049, pp. 1622-1626, 2011.

[16] A. G. Orive, P. Dip, Y. Gimeno et al., "Electrocatalytic and magnetic properties of ultrathin nanostructured iron-melanin films on Au(111)," Chemistry-A European Journal, vol. 13, no. 2, pp. 473-482, 2007.

[17] G. S. Huang, M. T. Wang, C. W. Su, Y. S. Chen, and M. Y. Hong, "Picogram detection of metal ions by melanin-sensitized piezoelectric sensor," Biosensors and Bioelectronics, vol. 23, no. 3, pp. 319-325, 2007.

[18] S. Chen, C. Xue, J. Wang et al., "Adsorption of $\mathrm{Pb}(\mathrm{II})$ and Cd(II) by squid Ommastrephes bartrami melanin," Bioinorganic Chemistry and Applications, vol. 2009, Article ID 901563, 7 pages, 2009.

[19] X. Yu, Z. Gu, R. Shao, H. Chen, X. Wu, and W. Xu, "Study on adsorbing chromium(VI) ions in wastewater by aureobacidium pullulans secretion of melanin," Advanced Materials Research, vol. 156-157, pp. 1378-1384, 2011.
[20] J. M. Gallas, K. C. Littrell, S. Seifert, G. W. Zajac, and P. Thiyagarajan, "Solution structure of copper ion-induced molecular aggregates of tyrosine melanin," Biophysical Journal, vol. 77, no. 2, pp. 1135-1142, 1999.

[21] Y. Liu and J. D. Simon, "Metal-ion interactions and the structural organization of Sepia eumelanin," Pigment Cell Research, vol. 18, no. 1, pp. 42-48, 2005.

[22] G. Prota, Melanins and Melanogenesis, Academic Press, San Diego, Calif, USA, 1992.

[23] D. L. Dehn, D. J. Claffey, M. W. Duncan, and J. A. Ruth, "Nicotine and cotinine adducts of a melanin intermediate demonstrated by matrix-assisted laser desorption/ionization time-of-flight mass spectrometry," Chemical Research in Toxicology, vol. 14, no. 3, pp. 275-279, 2001.

[24] H. Lee, S. M. Dellatore, W. M. Miller, and P. B. Messersmith, "Mussel-inspired surface chemistry for multifunctional coatings," Science, vol. 318, no. 5849, pp. 426-430, 2007.

[25] S. Ito and K. Wakamatsu, "Human hair melanins: what we have learned and have not learned from mouse coat color pigmentation," Pigment Cell and Melanoma Research, vol. 24, no. 1, pp. 63-74, 2011.

[26] R. M. Haywood, M. Lee, and C. Andrady, "Comparable photoreactivity of hair melanosomes, eu- and pheomelanins at low concentrations: low melanin a risk factor for UVA damage and melanoma?" Photochemistry and Photobiology, vol. 84, no. 3, pp. 572-581, 2008.

[27] Y. Liu, V. R. Kempf, J. B. Nofsinger et al., "Comparison of the structural and physical properties of human hair eumelanin following enzymatic or acid/base extraction," Pigment Cell Research, vol. 16, no. 4, pp. 355-365, 2003.

[28] J. M. Belitsky, "Aryl boronic acid inhibition of synthetic melanin polymerization," Bioorganic and Medicinal Chemistry Letters, vol. 20, no. 15, pp. 4475-4478, 2010.

[29] Q. F. Lü, M. R. Huang, and X. G. Li, "Synthesis and heavymetal-ion sorption of pure sulfophenylenediamine copolymer nanoparticles with intrinsic conductivity and stability," Chemistry-A European Journal, vol. 13, no. 21, pp. 6009-6018, 2007.

[30] A. Demirbas, E. Pehlivan, F. Gode, T. Altun, and G. Arslan, "Adsorption of $\mathrm{Cu}(\mathrm{II}), \mathrm{Zn}(\mathrm{II}), \mathrm{Ni}(\mathrm{II}), \mathrm{Pb}$ (II), and $\mathrm{Cd}(\mathrm{II})$ from aqueous solution on Amberlite IR-120 synthetic resin," Journal of Colloid and Interface Science, vol. 282, no. 1, pp. 20-25, 2005.

[31] D. M. Vieira, A. C. A. Da Costa, C. A. Henriques, V. L. Cardoso, and F. P. De França, "Biosorption of lead by the brown seaweed Sargassum filipendula-batch and continuous pilot studies," Electronic Journal of Biotechnology, vol. 10, no. 3, pp. 368-375, 2007.

[32] A. V. Jamode, M. Rao, B. S. Chandak, V. S. Jamode, and A. V. Parwate, "Applications of the inexpensive adsorbents for the removal of heavy metals from industrial wastewater: a brief review," Journal of Industrial Pollution Control, vol. 19, no. 1, pp. 114-134, 2003.

[33] L. Najder-Kozdrowska, B. Pilawa, A. B. Wieckowski, E. Buszman, and D. Wrześniok, "Influence of copper(II) ions on radicals in DOPA-melanin," Applied Magnetic Resonance, vol. 36, no. 1, pp. 81-88, 2009.

[34] J. B. Nofsinger, S. E. Forest, L. M. Eibest, K. A. Gold, and J. D. Simon, "Probing the building blocks of eumelanins using scanning electron microscopy," Pigment Cell Research, vol. 13, no. 3, pp. 179-184, 2000.

[35] B. Larsson and H. Tjalve, "Studies on the melanin-affinity of metal ions," Acta Physiologica Scandinavica, vol. 104, no. 4, pp. 479-484, 1978. 
[36] A. M. Potts and P. C. Au, "The affinity of melanin for inorganic ions," Experimental Eye Research, vol. 22, no. 5, pp. 487-491, 1976.

[37] Y. Zhai, Y. Liu, X. Chang, X. Ruan, and J. Liu, "Metal ion-small molecule complex imprinted polymer membranes: preparation and separation characteristics," Reactive and Functional Polymers, vol. 68, no. 1, pp. 284-291, 2008.

[38] M. G. Bridelli and P. R. Crippa, "Theoretical analysis of the adsorption of metal ions to the surface of melanin particles," Adsorption, vol. 14, no. 1, pp. 101-109, 2008.

[39] B. Szpoganicz, S. Gidanian, P. Kong, and P. Farmer, "Metal binding by melanins: studies of colloidal dihydroxyindolemelanin, and its complexation by $\mathrm{Cu}(\mathrm{II})$ and $\mathrm{Zn}(\mathrm{II})$ ions," Journal of Inorganic Biochemistry, vol. 89, no. 1-2, pp. 45-53, 2002.

[40] E. Buszman, B. Kwasniak, and A. Bogacz, "Binding capacity of metal ions to synthetic Dopa-Melanins," Studia Biophysica, vol. 125, no. 2, pp. 143-153, 1988. 


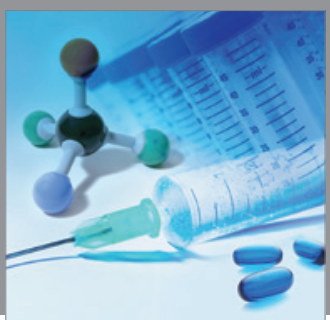

International Journal of

Medicinal Chemistry

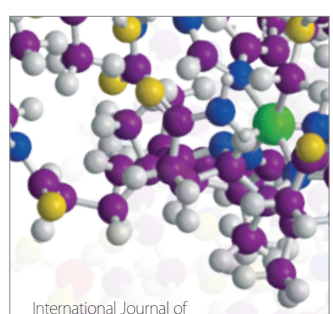

Carbohydrate Chemistry

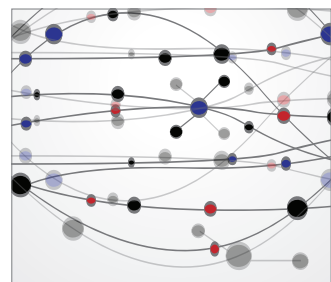

The Scientific World Journal
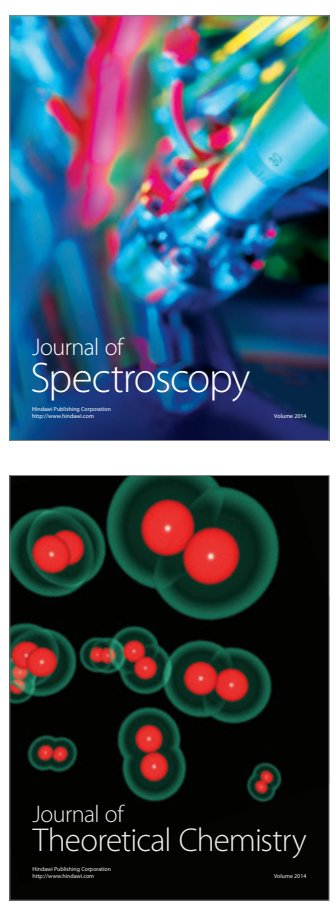
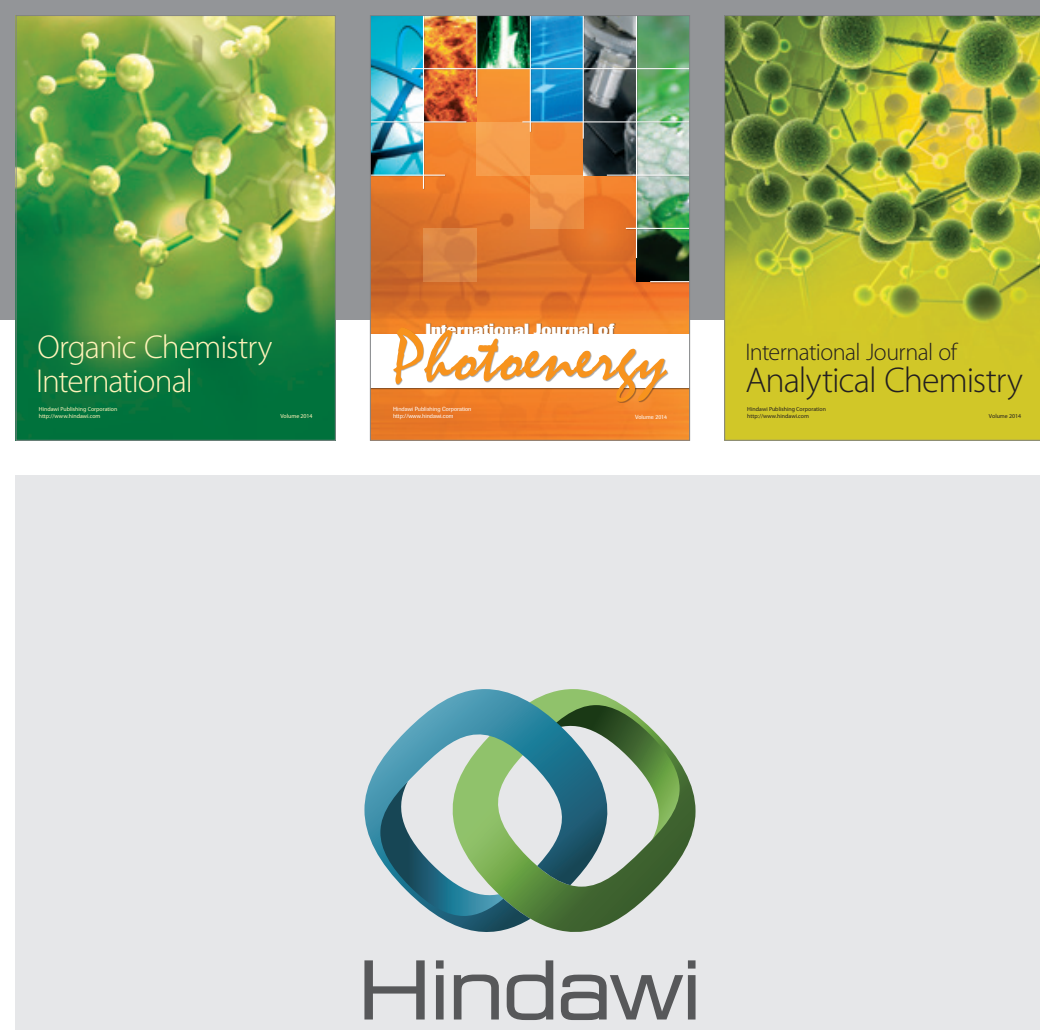

Submit your manuscripts at

http://www.hindawi.com
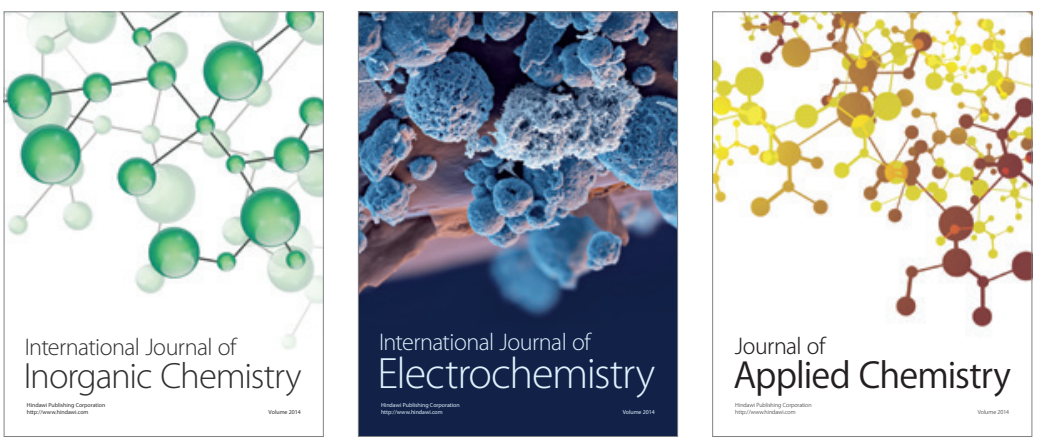

Journal of

Applied Chemistry
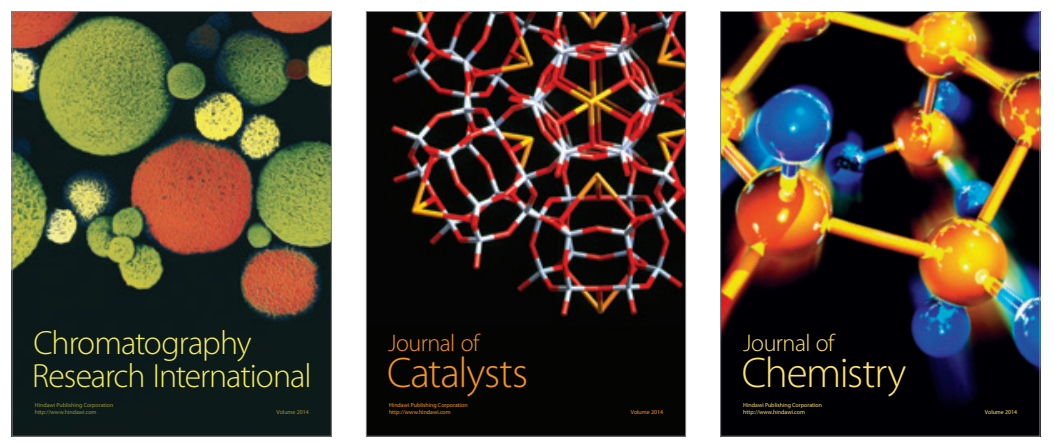
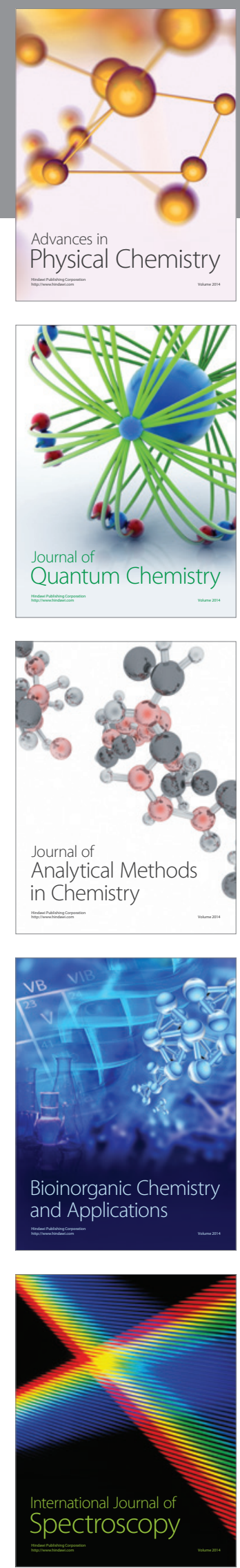